Artigo

\title{
A Educação Matemática pelas práticas e pesquisas tecidas na produção acadêmica: uma apresentação de potenciais tendências
}

\section{Mathematical Education through the practices and research that are woven into academic production: a presentation of potential trends}

\section{La educación matemática a través de las prácticas y la investigación que se entrelazan con la producción académica: una presentación de tendencias potenciales}

\author{
Luciane Mulazani dos Santos ${ }^{1}$ \\ iD [0000-0001-7617-7310]
}

\begin{abstract}
Resumo
Este artigo comenta os textos do Boletim online de Educação Matemática - BOEM que foram publicados em outubro de 2020, no número oito do volume quinze. Oito artigos, um ensaio, um relato de experiência e uma revisão são apresentados em seus contextos metodológicos, empíricos e teóricos que foram compartilhados por autores e autoras oriundos e oriundas de oito Estados brasileiros: Ceará, Mato Grosso do Sul, Minas Gerais, Paraná, Rio Grande do Norte, Rio Grande do Sul, Santa Catarina e São Paulo. Essas apresentações, além de evidenciarem as produções e sua regionalidade, levam a uma caracterização de uma panorama das Tendências em Educação Matemática que, de diferentes maneiras, teceram as práticas e as discussões apresentadas pelos pesquisadores, professores e grupos de pesquisa envolvidos. Como resultado, convidam-se os leitores e leitoras a mergulharem nos textos, bem como a refletirem sobre do uso de tecnologias no âmbito da Educação Matemática como fios que tecem diferentes potencialidades de práticas, de pesquisas, de ensino e de aprendizagem.
\end{abstract}

Palavras-chave: Educação Matemática. Produções acadêmicas. Tendências. Tecnologias.

\begin{abstract}
This text comments on the texts of the online Bulletin of Mathematical Education - BOEM that were published in October 2020, no number eight of volume fifteen. Eight articles, an essay, an experience report and a review are provided in their methodological, empirical and theoretical contexts that were shared by authors and authors from eight Brazilian states: Ceará, Mato Grosso do Sul, Minas Gerais, Paraná, Rio Grande do Norte, Rio Grande do Sul, Santa Catarina and São Paulo. These presentations, in addition to highlighting the productions and their regionality, lead to a characterization of a panorama of the Trends in Mathematical Education that, in different ways, wove the practices and researchs of the envolved people. As a result, readers are invited to immerse themselves in the texts, as well as to reflect on the use of technologies in the field of Mathematics Education as threads that weave different potentialities of practices, research, teaching and learning.
\end{abstract}

Keywords: Mathematical Education. Academic productions. Trends. Technologies.

\section{Resumen}

Este artículo comenta los textos del Boletín de Educación Matemática en línea - BOEM que fueron publicados en octubre de 2020, en el número ocho del volumen quince. Se presentan ocho artículos,

\footnotetext{
${ }^{1}$ Iuciane.mulazani@udesc.br, Doutora em Educação, Professora Associada, Universidade do Estado de Santa Catarina - UDESC, Florianópolis/SC/Brasil.
} 
un ensayo, un relato de experiencia y una revisión en sus contextos metodológicos, empíricos y teóricos que fueron compartidos por autores y autores de ocho estados brasileños: Ceará, Mato Grosso do Sul, Minas Gerais, Paraná, Rio Grande do Norte, Rio Grande do Sul, Santa Catarina y São Paulo. Estas presentaciones, además de resaltar las producciones y su regionalidad, conducen a una caracterización de un panorama de Tendencias en Educación Matemática que, de diferentes formas, tejió las prácticas y discusiones presentadas por los investigadores, profesores y grupos de investigación involucrados. Como resultado, se invita a los lectores a sumergirse en los textos, así como a reflexionar sobre el uso de las tecnologías en el campo de la Educación Matemática como hilos que entretejen diferentes potencialidades de prácticas, investigación, enseñanza y aprendizaje.

Palabras claves: Educación Matemática. Producciones académicas. Tendencias. Tecnologías.

\section{Introdução}

\section{Eu prefiro ser \\ Essa metamorfose ambulante \\ Do que ter aquela velha \\ Opinião formada sobre tudo ${ }^{2}$}

(Raul Seixas)

Este texto chega ao BOEM em meio a muitas mudanças.

Mudança de formato, pois agora temos nova diagramação para nossos textos.

Mudança de casa-cidade, pois nossa sede é Florianópolis desde janeiro deste ano.

Mudança de casa-plataforma, pois migramos o sistema da revista para a nova versão do OJS/PKP (Open Journal Systems/Public Knowledge Project).

E, como o mundo que enfrentou a pandemia de COVID-19 em 2020, mudança do normal.

Mudanças esperadas, mudanças planejadas, mudanças não imaginadas, mudanças não desejadas. 2020 vem sendo um ano assim, de mudanças, no amplo espectro da metamorfose. $O$ que me remeteu à composição de Raul.

Assim, para abrir este texto e refletir sobre a edição que ora publicamos, não consegui pensar em uma referência melhor do que a Metamorfose Ambulante, com o desejo do não querer ter "aquela velha opinião formada sobre tudo" para que, frente às mudanças, possa metamorfosear, superar e crescer.

Fez sentido essa reflexão também quando analisei os dez textos aceitos para publicação na edição 15 do volume 8 do BOEM de outubro de 2020. Vendo o conjunto, percebi como ele explicita práticas e pesquisas relacionadas ao que entendemos como Tendências em Educação Matemática (e suas metamorfoses ao longo do tempo e nos diferentes espaços). Pensar sobre as mudanças, sobre a passagem do tempo, sobre os caminhos que trilham um/a pesquisador/a e um/a professor/a, na nossa área, me levou aos modos como elas (as tendências) encorpam os fios com os quais tecemos nossas concepções, ações, intenções, planos e comunicações. Agradeço aos autores e às autoras dos textos por contribuírem para essa reflexão e por escolherem o BOEM para divulgação de suas produções.

\footnotetext{
${ }^{2}$ Letra da música "Metamorfose Ambulante", do cantor e compositor brasileiro Raul Seixas (1945-1989), gravada em 1973 em Krig-há, Bandolo!, seu primeiro LP (long-play).
} 
É então sobre isto que se trata o texto desse artigo: como os dez publicados no BOEM, em meio à pandemia de COVID-19, com nova plataforma, em nova cidade, podem provocar metamorfoses naquilo que a Tendências em Educação Matemática nos tecem enquanto professores/as e pesquisadores/as.

\section{Fios com o que se tecem aquilo que nos vestem}

As chamadas Tendências em Educação Matemática são recorrentemente acionadas nas práticas e nas pesquisas da área, como fios que tecem aquilo que vestem a constituição docente e de pesquisa. Ao longo do tempo, elas foram caracterizadas de diversas formas por diferentes autores. Para trazer alguns deles para essa conversa, referencio Lopes e Borba (1994), Fiorentini (1995), D’Ambrósio (1997), Bicudo (1999), Fiorentini (2003), Bicudo e Borba (2004), Miguel, Garnica, Igliori e D’Ambrósio (2004) e Kalinke e Mocrosky (2015). Não há unanimidade na discriminação (e delimitação) daquilo que é ou daquilo que não é uma Tendência em Educação Matemática, mas vemos que isso não é um problema, porque o essencial - aquilo que junta os fios - é consistente.

Os textos publicados na edição do BOEM aqui comentada apresentam e discutem temas, contextos e referenciais ${ }^{3}$ teóricos e empíricos que podem ampliar nossas compreensões sobre a Educação Matemática e suas tendências.

Um cenário dos fios tecidos pelos/as autores/as dos textos publicados - dentre artigos, relatos de experiência, ensaios ou revisões - pode ser conhecido por meio das nuvens de palavras que seguem, formadas a partir dos títulos dos trabalhos (Figura 1) e das palavraschave (Figura 2). Esses fios nos mostram evidências que podem significar o envolvimento com as tendências que constroem a Educação Matemática segundo interpretações dos/as autores/as. Além disso, as nuvens ressaltam os temas tocados pela edição, os quais são comentados nos tópicos seguintes.

Figura 1 - nuvem de palavras formada a partir dos títulos dos textos publicados

Figura 2 - nuvem de palavras formada a partir das

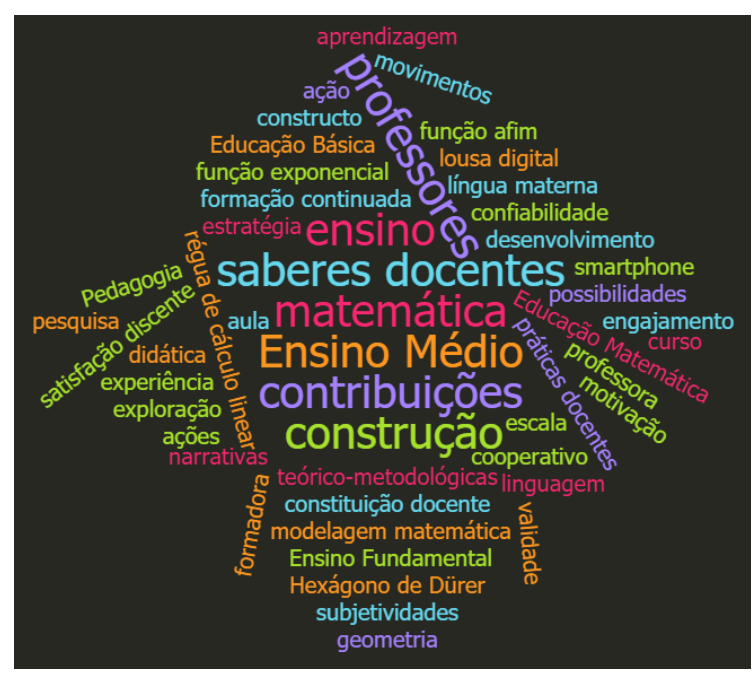
palavras-chave dos textos publicados

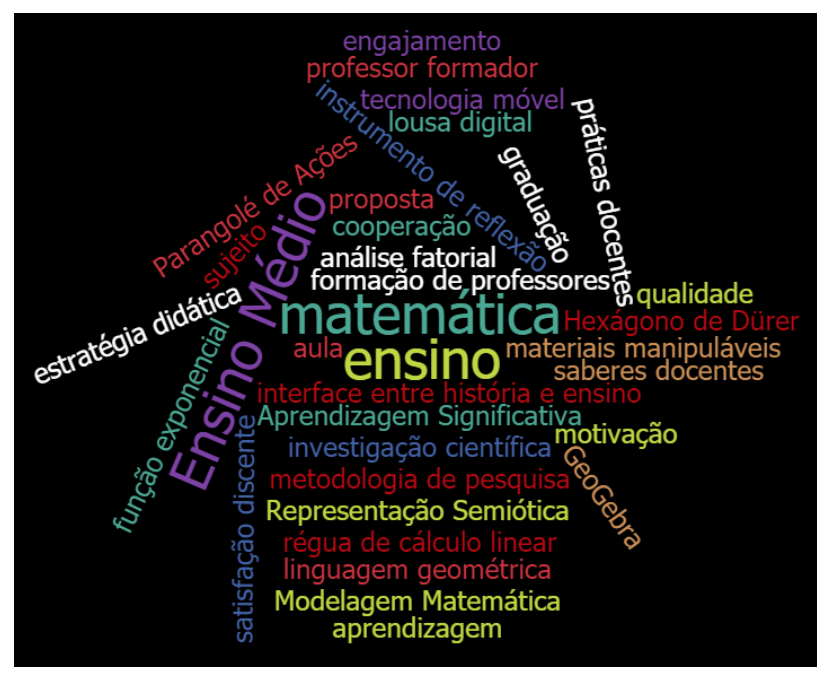

Fonte: a autora, 2020.

Fonte: a autora, 2020.

\footnotetext{
${ }^{3}$ A respeito das referências mencionadas neste artigo, ressalto que não foram citadas todas as que foram utilizadas pelos autores e autoras em seus textos. Para conhecimento na íntegra, recomendo aos leitores e leitoras que consultem os artigos, relatos de experiência, ensaios e revisões publicados nesta edição.
} 


\subsection{As contribuições da régua de cálculo linear na construção dos saberes e das práticas docentes}

"As contribuições da régua de cálculo linear na construção dos saberes e das práticas docentes" - de Andressa Gomes dos Santos (mestranda no Instituto Federal de Educação, Ciência e Tecnologia do Ceará), Adriana Nogueira de Oliveira (mestranda na Universidade Estadual do Ceará) e Ana Carolina Costa Pereira (docente adjunta da Universidade Estadual do Ceará) - é um artigo que nos aproxima da História da Matemática e dos estudos do GPEHM (Grupo de pesquisa em Educação e História da Matemática) para nos mostrar as repercussões do grupo relacionadas à discussão sobre possíveis relações entre a História da Matemática, o ensino e a formação inicial e continuada de professores.

Ao analisarem a participação de onze estudantes de licenciatura em matemática e um professor de matemática da rede estadual de ensino do Ceará em um curso de extensão universitária oferecido em março de 2019 pelo Laboratório de Matemática e Ensino (LABMATEN) da Universidade Estadual do Ceará (UECE), as autoras nos mostram suas conclusões a respeito das práticas realizadas e nos fazem refletir sobre os modos de inserção de artefatos históricos - retratam, especificamente, a régua de cálculo linear - no processo de construção de conhecimento na formação de professores.

As autoras destacam-se os seguintes interlocutores teóricos: Miguel (1997); D’Ambrósio (2007); Baroni, Teixeira e Nobre (2011) e Bissi (2014), para discutirem a inserção da história da matemática no ensino e Shulman (1986) para debaterem categorias de conhecimentos importantes para a formação docente.

\subsection{Contribuições da Modelagem Matemática para o desenvolvimento de ações de motivação e engajamento no Ensino Médio}

O artigo "Contribuições da Modelagem Matemática para o desenvolvimento de ações de motivação e engajamento no Ensino Médio" - de Neuber Silva Ferreira (Professor do Instituto Federal de Educação, Ciência e Tecnologia de Minas Gerais) e Carlos Fernando Araújo Junior (Professor do Programa de Pós-Graduação em Ensino de Ciências e Matemática da Universidade Cruzeiro do Sul) - discutem a Modelagem Matemática apoiada em tecnologias digitais móveis (smartphones) e nos mostram relações entre sua utilização com estudantes de Ensino Médio e as condições de motivação e engajamento, defendidas pelos autores como fatores importantes para melhoria da aprendizagem.

A pesquisa de doutorado de Neuber Silva Ferreira, que derivou o artigo, foi qualitativa e realizada no primeiro e segundo trimestres letivos de 2019, com procedimentos metodológicos de Design Based Research (PLOMP; NIEVEEN, 2013), com participação de oitenta estudantes de duas turmas de primeiro ano do Ensino Médio de um Instituto Federal de Minas Gerais, o professor das turmas e o pesquisador.

Na pesquisa completa, os conteúdos de matemática noções de conjuntos, conjuntos numéricos, funções e função afim foram trabalhados nas atividades de modelagem "Números racionais, cores e música" (RODRIGUES, 2008) , "Problema da conta de água do condomínio" (VIDIGAL, 2013) e "Como é feito o cálculo das corridas de táxi"; já os conteúdos funções quadrática, exponencial, logarítmica e modular fizeram parte das atividades "Parábolas na arquitetura" e "Modelagem na mineração"; os aplicativos utilizados para apoio do ensino e aprendizagem nos smartphones foram: Socrative Student e Teacher, Geogebra, WhatsApp e 
YouTube. No artigo, os autores apresentam e discutem a atividade de Modelagem Matemática "Modelagem e Mineração".

Os autores mostram, no artigo, como os resultados evidenciaram que a Modelagem Matemática, em atividades investigativas apoiadas com o uso de smartphone, contribuiu para aprendizagem dos conteúdos de matemática envolvidos, para promover ações de motivação e engajamento dos estudantes participantes, bem como propiciou que eles desenvolvessem habilidades para reconhecimento e utilização de etapas relacionadas a essa Tendência em Educação Matemática, tais como detecção de variações, realização de previsões, documentação, argumentação e percepção sobre como modelos são gerados à luz da incerteza. São destacadas as interlocuções com os seguintes referenciais: Almeida e Dias (2004), Malheiros (2012), Ferreira (2013), Kaiser (2014), Blum (2015) e Silva (2018) para discusão sobre a Modelagem Matemática e sua inserção em sala de aula; Ramos, Tristh e Salvi (2011), Bzuneck, Megliato e Rufini (2013), Ali e Hassan (2018), Camargo, Camargo e Souza (2019) e Farias e Vaz (2019) para tratar dos temas motivação e engajamento.

\subsection{Da ação à construção: uma experiência com smartphone e trabalho cooperativo no ensino de funções afins no Ensino Fundamental}

O ensaio "Da ação à construção: uma experiência com smartphone e trabalho cooperativo no ensino de funções afins no Ensino Fundamental" - de Rodrigo Sychocki da Silva (professor na Universidade Federal do Rio Grande do Sul) e Shéridan dos Reis Pinto (Professora da rede pública no Estado de Santa Catarina) - analisa as contribuições de ações cooperativas, apoiadas pelo uso de smartphones, para construção de conceitos sobre função afim por três estudantes de oitavo ano do Ensino Fundamental de uma escola privada de Porto Alegre/RS. Trata-se de um recorte de uma pesquisa de mestrado em Ensino de Matemática, cujos dados foram coletados em novembro de 2019.

$\mathrm{Na}$ interlocução teórica, os autores apoiam-se no conceito de cooperar de Piaget (1973), em ideias como as de Bairral (2017), White e Martin (2014), Batista (2011), Martins et al (2018) e Sonego (2019) sobre o uso de smartphones na Educação Matemática.

Os autores apresentam as atividades realizadas, descrevem como os smartphones apoiaram o processo de trabalho cooperativo para o desenvolvimento das atividades e a construção de conhecimentos por parte dos estudantes. Foi utilizado o aplicativo GeoGebra Graphing Calculator nas tarefas sobre funções afins nos smartphones dos estudantes. $\mathrm{Na}$ análise, os autores buscaram as evidências de cooperação registradas em áudios gravados pelos estudantes nos diálogos que mantiveram para discussão das tarefas. Concluíram que o uso dos smartphones tanto contribui para melhor compreensão do conteúdo matemático quando os estudantes utilizaram o aplicativo do GeoGebra - quanto ampliaram as possibilidades de comunicação e cooperação entre os estudantes, pela ampliação dos espaços de diálogo. Dessa forma, segundo os autores, a ação coletiva, da forma como proposta, convergiu para uma construção de conhecimentos matemáticos.

\subsection{Função exponencial: uma estratégia didática aplicada no Ensino Médio}

O relato de experiência "Função exponencial: uma estratégia didática aplicada no Ensino Médio" - de Cristiana Monique Feltes Sivert (professora de Educação Básica no Rio Grande do Sul), Cassiano Scott Puhl (doutorando no Programa de Pós-Graduação em Educação em Ciências e Matemática da Pontifícia Universidade Católica do Rio Grande do Sul) 
e Elaine Corrêa Pereira (professora da Universidade Federal do Rio Grande/RS) - nos apresenta atividades realizadas em uma escola pública com uma turma de primeiro ano de Ensino Médio sobre conteúdos de função exponencial e matemática financeira na perspectiva da Teoria de Aprendizagem Significativa de David Ausubel.

As atividades relatadas e analisadas foram aplicadas para vinte e um estudantes pela primeira autora - que também era a professora da turma - no segundo semestre letivo de 2017, em 16 horas/aula no turno regular. A proposta e o desenvolvimento da estratégia didática basearam-se na Teoria de Aprendizagem Significativa de Ausubel (2003) em seis etapas: aplicação de questionário aos estudantes com o objetivo de verificar e ativar subsunçores; atividade de dobradura de papel para explorar conceitos gerais sobre função exponencial; exploração dos conceitos específicos: potenciação de um produto, divisão de potências de mesma base, potenciação de potência, potenciação de fração e potência com expoente negativo; oficina de jogos para estabelecer relações entre os conhecimentos matemáticos e situações contextualizadas; exploração de conceitos mais específicos da função exponencial aplicados em Matemática Financeira; aplicação de um novo questionário para analisar aprendizagens desenvolvidas pelos estudantes ao participarem da estratégia didática.

Apoiados em interpretações da Teoria de Aprendizagem Significativa (AUSUBEL; NOVAK; HANESIAN, 1980; AUSUBEL, 2003; MOREIRA, 1997, 2008a, 2008b, 2011; MOREIRA; MASINI, 2006), os autores concluíram que a maioria dos estudantes participantes compreenderam os conceitos de função exponencial e os associaram a situações do cotidiano, o que evidenciou que, na experiência, houve oportunidades de aprendizagem da matemática de forma significativa e contextualizada.

\subsection{Linguagem matemática, ensino de Geometria e língua materna: saberes docentes de uma professora formadora em um curso de Pedagogia}

"Linguagem matemática, ensino de Geometria e língua materna: saberes docentes de uma professora formadora em um curso de Pedagogia" - de Pedro Augusto Mazini dos Santos (mestrando na Universidade Estadual de Maringá) e Marcelo Carlos de Proença (Professor adjunto da Universidade Estadual de Maringá) - é um artigo que apresenta uma discussão sobre saberes docentes mobilizados na articulação entre linguagem matemática e língua materna em uma disciplina de Metodologia de Ensino de Matemática de um curso de Pedagogia de uma universidade pública localizada no Estado do Paraná.

Para tal, analisam um recorte de uma pesquisa de mestrado com dados sobre práticas pedagógicas da professora formadora ao defender o ensino de Geometria por meio de atividades práticas e materiais manipuláveis. Concluem sobre a pesquisa indicando a necessidade de aprofundamento de saberes disciplinares para estabelecimento de articulação entre linguagem matemática e materna.

Os autores problematizam o ensino de Geometria - apoiados em Pavanello (1989, 1993, 2004a, 2004b), Pavanello et al. (1995), Nacarato (2000), Curi (2004, 2005) -; a atuação do professor formador da área de matemática em cursos de Pedagogia - como em Curi (2005); De Almeida e Lima (2012) - e os saberes docentes conforme Tardif (2002). 


\subsection{Lousa digital e aula de matemática: movimentos de aprendizagem em uma turma de primeiro ano do Ensino Médio}

O artigo "Lousa digital e aula de matemática: movimentos de aprendizagem em uma turma de primeiro ano do Ensino Médio" - de Sérgio Freitas de Carvalho (Professor do Ensino Básico, Técnico e Tecnológico no Instituto Federal de Mato Grosso do Sul) e Suely Scherer (Professora Associada na Universidade Federal de Mato Grosso do Sul) - discute a aprendizagem de conteúdos de geometria plana (área de retângulos) com uso de lousa digital e do software Geoplano Digital em uma turma de Ensino Médio em uma escola pública de Campo Grande/MS em 2016/2017. Temos, com esse texto, uma oportunidade de conhecer e refletir sobre um estudo a respeito da utilização da tecnologia digital para/na Educação Matemática.

Com reflexões ancoradas nas pesquisas de mestrado e de doutorado de Sérgio Freitas de Carvalho orientadas por Suely Scherer, somos apresentados a uma proposta teórica para análise de aprendizagens com lousa digital denominada "Ciclo de Ações Coletivo", baseada no Ciclo de Ações proposto em Valente (2005), na Psicologia Cultural descrita em Valsiner (2012) e em metáfora da obra O Parangolé, do artista plástico Hélio Oiticica.

Os autores descrevem a analisam atividades realizadas na aula de matemática Segundo conclusões obtidas, as interações entre estudantes e professor, e deles com a lousa digital constituíram "Ciclos de Ação Coletivos", sendo que a lousa digital pode favorecer o compartilhamento de ideias para construção individual e coletiva de conhecimento por parte dos estudantes e as ações do professor foram fundamentais na constituição dos movimentos de aprendizagem.

\subsection{Pesquisa em educação matemática e subjetividades: possibilidades teórico- metodológicas}

Em "Pesquisa em educação matemática e subjetividades: possibilidades teóricometodológicas", Marcelo Bezerra de Morais (professor da Universidade do Estado do Rio Grande do Norte), Jorge Ricardo Ferreira Braúna (Polícia Rodoviária Federal/RN, Mossoró) e Daniel Syllas Pereira de Souza (professor da educação básica na rede municipal de Areia Branca/RN) discutem potências da História Oral, da Sociopoética e da Cartografia para o desenvolvimento de pesquisas em Educação Matemática, como referenciais teóricometodológicos que abordam a subjetividade.

Os autores discutem como as experiências de pesquisadores em Educação Matemática, tais como Skovsmose (2014) e D’Ambrósio (2015) nos mostram que a qualidade dos atos de ensinar e de aprender não podem ser separadas do estado de espírito daquele que ensina e aprende, pois nossas relações com os conteúdos matemáticos não são dissociadas das pessoas e dos ambientes que nos cercam. A subjetividade é discutida segundo autores como Morin (1996), Guattari e Rolnik (2005), Deleuze e Guattari (1995), Foucault (1979), Larrosa (2016) e Halbwachs (2006), Woodward (2012). A História Oral é apresentada conforme Garnica (2010, 2019) e Garnica, Silva e Fernandes (2010). Sobre a sociopoética, Gauthier (2015), Guattari (2001), Silveira et al (2008) sustentam sua base de discussão no texto. O método de pesquisa cartográfico é discutido à luz de Passos, Kastrup e Escóssia (2009), Costa (2014), Ribeiro (2015).

As compreensões dos autores sobre as teorias e os procedimentos envolvidos a partir da interlocução teórica foram entremeadas pela discussão com a empiria de seus estudos 
anteriores: Morais (2017) sobre História Oral, Braúna (2020) sobre Sociopoética e Souza (2020) sobre Cartografia. Ao apresentarem as potencialidades de pesquisas sobre sujeitos e suas subjetividades, declaram sua defesa da importância desse tipo de estudo para elaboração de novas compreensões sobre o mundo e sobre a Educação Matemática.

\subsection{Um estudo sobre as contribuições das narrativas na formação continuada de professores de Matemática e a constituição docente}

"Um estudo sobre as contribuições das narrativas na formação continuada de professores de Matemática e a constituição docente" - de Rafael Marques dos Santos (mestrando da Universidade Federal da Fronteira Sul, Cerro Largo/RS), Sandra Maria Wirzbicki (professora da Universidade Federal da Fronteira Sul, Cerro Largo/RS) e Danusa de Lara Bonotto (da Universidade Federal da Fronteira Sul, Cerro Largo/RS) - é uma revisão de dissertações e teses publicadas na Biblioteca Digital Brasileira de Teses e Dissertações entre 2009 e 2019 sobre formação continuada de professores de matemática.

O levantamento bibliográfico utilizou os descritores "formação continuada em matemática, narrativas e constituição docente" e, ao final, resultou em quinze trabalhos, cuja análise, na íntegra, utilizou os procedimentos da Análise de Conteúdo conforme Bardin (1979). Segundo os autores, dos trabalhos analisados, três são da área de Ensino de Ciências e Matemática e doze são da área de Educação/Educação Matemática; três tratam dos Anos Iniciais e/ou Educação Infantil, dois do Ensino Fundamental, nenhum do Ensino Médio e dez da Educação Superior e/ou Pós-Graduação, com evidências de que utilizaram diferentes metodologias e referenciais teóricos para discutirem os temas.

Os resultados relatados pelos autores da revisão evidenciam ponderações sobre como a formação docente se mostra como tema nas pesquisas quando articulada com a utilização de narrativas e com a constituição docente, bem como nos colocam em contato com o vasto referencial teórico que sustentou tais estudos, tais como Reis (2008), Nóvoa (1992a; 1992b; 1995a, 1995b), Fiorentini (2006), Tardif (2003), Nacarato (2000) e Ponte (2000). Em sua conclusão, os autores destacam a necessária atenção no contexto escolar para narrativas de professores em formação inicial e continuada, para que a constituição docente seja objeto de reflexão crítica em todos os níveis de ensino.

\subsection{Uma exploração do Hexágono de Dürer com professores de Matemática da Educação Básica}

"Uma exploração do Hexágono de Dürer com professores de Matemática da Educação Básica" - de Fabrícia de Carvalho Paixão (especialista em Educação Inclusiva), Mariana Moran (professora da Universidade Estadual de Maringá) e Veridiana Rezende (professora da Universidade Estadual do Paraná) - é um artigo que discute, à luz de Raymond Duval, a utilização de diferentes tipos de Registros de Representação Semiótica em atividades sobre Geometria Fractal (Hexágono de Dürer) elaboradas por quatorze professores de Matemática da Educação Básica participantes do Programa de Desenvolvimento Educacional (PDE) do Estado do Paraná.

Em 2016, as pesquisadoras propuseram, aos professores participantes, um curso com duração de quatro horas para construção do fractal hexagonal tipo Dürer, com uso do GeoGebra, no Laboratório de Informática do campus de Campo Mourão da Universidade Estadual do Paraná. Coletaram os dados por meio de observação e de questionários aplicados 
aos participantes, que perguntou a eles que conteúdos de matemática poderiam ser explorados durante e após a construção daquele fractal e propôs que elaborassem uma atividade que contemplasse os conteúdos que mencionaram. Após análise desses dados, identificaram que os conteúdos estruturantes (Funções, Geometria, Grandezas e Medidas, Números e Álgebra) foram apontados pelos professores participantes com possibilidades de ensino por meio de fractais; e concluíram que, nas atividades propostas pelos participantes, a representação numérica foi a mais indicada, enquanto a representação algébrica foi evidenciada na proposta de apenas um professor. Outra conclusão importante foi relacionada ao uso da tecnologia: as positivas contribuições do uso de diferentes Registros de Representação Semiótica em atividades de Geometria Fractal quando softwares, como o GeoGebra, são utilizados no processo.

Além da interlocução com Duval $(1999,2012)$, as autoras se basearam em Moretti (2002) para discutirem os Registros de Representação Semiótica. As geometrias não euclidianas (fractal) foram discutidas a partir de trabalhos como os de Barbosa (2005), Cury e Leivas (2008), Bagio e Rolkouski (2014) e Bagio (2015).

\subsection{Validade de construto e confiabilidade: uma escala para a satisfação discente}

$\mathrm{O}$ artigo "Validade de construto e confiabilidade: uma escala para a satisfação discente" - de Vanussa Braga Rezende Dutra (Discente da Universidade Federal do Rio Grande/RS) e Viviane Leite Dias de Mattos (Professora da Universidade Federal do Rio Grande/RS) - apresenta a validação de constructo de um instrumento que foi desenvolvido para medir o nível de satisfação de discentes de cursos de graduação em Matemática.

Foi constituída uma amostra formada por cento e quarenta e dois discentes de cursos de Licenciatura em Matemática ou Matemática Aplicada de duas instituições de Ensino Superior do sul do Estado do Rio Grande do Sul. Houve Análise Exploratória de Dados e avaliação de sua fatorabilidade, para posterior identificação e extração de fatores, feitas por Análise de Componentes Principais e Análise Fatorial Exploratória com o Método dos Eixos Principais, aplicadas à pontuação da importância de cada item. Além disso, foi feita análise de confiabilidade pelo coeficiente Alfa de Cronbach. Com a análise, as autoras identificaram "Recursos materiais e humanos", "Professor", "Metodologia" e "Disciplinas" como fatores que conseguiram explicar $68,98 \%$ da variância por meio de 19 itens.

A contextualização do problema estudado remete à necessidade de resolver problemas de cursos do Ensino Superior, tais como reprovação e evasão escolar nos primeiros semestres de cursos de Matemática e de, na esteira desse desafio, propiciar satisfação aos discentes a partir do cumprimento de suas expectativas relacionadas ao curso que escolheram. No texto, as autoras apresentam referenciais utilizados para a construção do instrumento, a metodologia utilizada para análise dos dados e os resultados encontrados. Dentre as referências adotadas, Cock e Halvari (2001), Cruz e Silva (2019), Davis e Swanson (2001), Sultan e Wong (2013) embasam o tema satisfação; Cunha, Gomes e Beck (2016), Schleich, Polydoro e Santos (2006) e Soares, Vasconcelos e Almeida (2002) embasaram o desenvolvimento do instrumento.

Segundo resultados encontrados pelas autoras relacionados à satisfação dos discentes, a amostra investigada considerou que aspectos relacionados à infraestrutura oferecida pela instituição eram mais importantes que aspectos ligados à aprendizagem. Ressaltam, porém, que os itens "comprometimento com o ensino por parte dos professores" e "qualificação profissional dos professores" foram bastante valorizados pelos participantes da pesquisa. 


\section{Metamorfose de fios e de processos: tecidos que nos vestem}

Os campos de pesquisa e da atuação da Educação Matemática são amplos e autônomos. Renovam-se quando buscam potenciais soluções para problemas relacionados ao ensino e à aprendizagem de matemática em sua relação com as pessoas e com o mundo.

Tecendo um breve fio histórico sobre as transformações da Educação Matemática no Brasil e suas tendências, começo com o resgate de Lopes e Borba (1994, p. 50), que nos contaram que "buscando soluções para os problemas da Educação Matemática foram desenvolvidas muitas formas de trabalho, embasadas em diferentes teorias ou apresentadas sob diferentes posições epistemológicas, com a preocupação de melhorar a aprendizagem", para lembrar que já antes dessa fala e, continuamente, depois dela, diferentes pessoas e grupos se movem em escolhas - as tendências - que guiam seus modos de ser, trabalhar e pensar a área. As discussões que encontramos em obras como Fiorentini (1995), D’Ambrósio (1997), Bicudo (1999), Fiorentini (2003), Bicudo e Borba (2004), Miguel, Garnica, Igliori e D’Ambrósio (2004) e Kalinke e Mocrosky (2015) são exemplos de estudos e contextos da pesquisa e do ensino em Educação Matemática que nos acompanham ao longo do tempo nosso tempo de formação e de ação - para nos inserir na área segundo aquilo que acreditamos ser a tendência que nos abraça, seja Etnomatemática, Tecnologias, Modelagem Matemática, Resolução de Problemas, Educação Matemática Crítica, História da Matemática, Filosofia da Matemática ou outras tais as quais, dentro do escopo em que se apresentam, nos mostram uma maneira de trabalhar na/para a área. Fecho essa reflexão com os pensamentos que construí com o Professor Valdir, também colega da Editoria do BOEM, em Santos e Damázio Júnior (2015, p. 64) com a intenção de provocar reflexões sobre os caminhos da educação matemática e suas (novas) tendências construídas na pós-modernidade, quando a verdade deixa de ocupar posição central, o que dá espaços a várias verdades e várias formas de se relacionar com o conhecimento, permitindo "novas abordagens e novas possibilidades tanto para o conhecimento matemático, para a pesquisa em educação matemática, quanto para o ensino de matemática", ou seja, há espaços abertos para (re)construção de (novas) tendências.

Nesse contexto de discussão sobre Tendências em Educação Matemática, os textos publicados nesta edição se vestiram de diferentes perspectivas para comunicar os seus achados. A sua leitura, além de nos colocar em contato com o universo das pesquisas e práticas apresentadas e seus resultados, dá aos leitores a oportunidade de ampliar conhecimentos sobre alcances e propósitos da Educação Matemática na época em que vivemos.

É interessante observar que, por mais que possamos identificar a predominância de uma determinada tendência nos estudos e pesquisas, elas fazem parte de contextos que, na maioria das vezes, envolvem outras questões que também motivam importantes discussões para a área da Educação Matemática. São os diversos fios dos tecidos que nos vestem. Como exemplo, comento os trabalhos que estão em desenvolvimento no NEPESTEEM - Núcleo de Estudo e Pesquisa em Tecnologia Educacional e Educação Matemática, grupo de pesquisa que lidero na UDESC, certificado pelo CNPq.

Em outubro de 2020, há em andamento sob minha orientação, dez pesquisas acadêmicas no PPGE ${ }^{4}$ - sendo quatro de doutorado e seis de mestrado - e duas pesquisas no

\footnotetext{
${ }^{4}$ Mestrado e Doutorado acadêmicos em Educação - FAED/PPGE - Programa de Pós-Graduação em Educação: https://www.udesc.br/faed/ppge
} 
mestrado profissional do PPGECMT ${ }^{5}$. Das doze, quatro discutem temas diretamente ligados à Tecnologia Educacional: duas de doutorado que abordam o desenvolvimento do pensamento computacional na Educação Básica e duas de mestrado (uma no acadêmico e outra no profissional) que investigam a utilização de tecnologias de realidade mista na formação de professores. Os problemas de pesquisa dos demais projetos envolvem formação de professores, constituição de saberes e da profissionalidade docentes, educomunicação, avaliação e políticas públicas educacionais. O que quero observar é a forma como uma das tendências em Educação Matemática - Tecnologias [e variações desse nome] - perpassam nossos estudos no NEPESTEEM. As duas pesquisas de doutorado cujos objetivos focam em tecnologia o fazem no âmbito de uma discussão sobre currículo. As pesquisas de mestrado acadêmico que discutem as potencialidades da realidade mista fazem-se em torno de um debate voltado à formação de professores para construção de conhecimentos para o ensino. Ou seja, ainda que, de certa forma, possamos caracterizá-las como pesquisas sobre tecnologia educacional, há outros tecidos que ou sustentam ou são sustentados sobre as ideias a ela referente. Do outro lado, as pesquisas com outros temas têm, de uma forma ou outra, apoio de recursos acessíveis pela via da tecnologia. $O$ que quero dizer aqui é que, dentre as formas de trabalho em Educação Matemática carimbadas como tendências - independentemente da autoria dessa referência -, a Tecnologia etc. ${ }^{6}$ talvez seja a que mais mobiliza, em seus entornos, uma variedade de debates em torno de relevantes temas para a área da Educação Matemática na perspectiva de (novas) tendências construídas na pós-modernidade (SANTOS e DAMÁZIO JÚNIOR, 2015). Isso, suspeito, porque tecnologia é, hoje, mais do que uma tendência: é um produto social posto, o qual, por conta de suas características e potencialidades, se transforma a cada discussão ou vivência, sejam elas acadêmicas ou não.

\section{4 "Eu quero dizer agora o oposto do que eu disse antes" (SEIXAS, Raul)}

Se comecei conversando com a Metamorfose Ambulante de Raul Seixas para falar sobre as mudanças dos fios que tecem nossas práticas e nossas pesquisas em Educação Matemática e cheguei a uma costura com a pós-modernidade, encerro este texto ainda com alusão à obra de Raul Seixas, com um verso que nos dá potência para seguirmos em transformação.

À guisa de conclusão, em meu nome e em nome do BOEM, agradeço a todos os autores e autoras dos textos e aos/às pareceristas quem, com suas contribuições, tornaram possível a publicação da edição regular de 2020, a qual, inevitavelmente, teve seus processos editoriais impactados pela pandemia de COVID-19. Sobrevivemos, transformamos e seguiremos tecendo nossos fios na Educação Matemática. Aos leitores e às leitoras, igualmente agradeço, convido à leitura e desejo metamorfoses.

\section{Referências}

ALI, M.; HASSAN, N. Defining concepts of student engagement and factors contributing to their engagement in schools. Creative Education, v. 9, n. 14, p. 2161-2170, 2018.

5 Mestrado profissional - CCT/PPGECMT - Programa de Pós-Gradução em Ensino de Ciências, Matemática e Tecnologias: https://www.udesc.br/cct/ppgecmt

${ }^{6}$ Chamei de Tecnologia etc. para representar todos os possíveis nomes sob quais tal tendência pode ser retratatada. 
ALMEIDA, L. M. W.; DIAS, M. R. Um Estudo sobre o Uso da modelagem matemática como Estratégia de Ensino e Aprendizagem. Bolema, n. 22, p. 19-35, Rio Claro, 2004.

AUSUBEL, David. P. Aquisição e retenção de conhecimento: uma perspectiva cognitiva. Lisboa: Paralelo, 2003.

AUSUBEL, David. P.; NOVAK, Joseph D.; HANESIAN, Helen. Psicologia Educacional. 2. ed. Rio de Janeiro: Interamericana, 1980.

BAGIO, V. A; ROLKOUSKI, E. A implementação das diretrizes curriculares da educação do estado do Paraná e o conteúdo de Geometrias não euclidianas: versões de uma mesma história. In: EPREM 2014, Campo Mourão. Anais do XII Encontro Paranaense de Educação Matemática, 2014. p.1-13.

BAGIO, Viviane Aparecida. O que dizem as produções paranaenses quanto ao ensino das geometrias não euclidianas a partir da publicação das Diretrizes Curriculares da Educação do Estado do Paraná. BOEM - Boletim online de Educação Matemática, Joinville, v. 8, n. 4, p.45-65, jul. 2015.

BAIRRAL, M. A. As manipulações em tela compondo a dimensão corporificada da cognição matemática. Jornal Internacional de Estudos em Educação Matemática, São Paulo, v. 10, n. 2, p. 104-111, 2017.

BARBOSA, R.M. Descobrindo a geometria Fractal - para a sala de aula. 2. Ed. Belo Horizonte: Autêntica, 2005.

BARDIN, Laurence. Análise de conteúdo. Lisboa: Edições 70, 1979.

BARONI, Rosa Lúcia; TEIXEIRA, Marcos Vieira; NOBRE, Sérgio Roberto. História da Matemática em contextos da Educação Matemática: contribuições do GPHM. Boletim de Educação Matemática, Rio Claro, v. 25, n. 41, p.153-171, dez. 2011.

BATISTA, S. C. F. M-learnmat: Modelo pedagógico para atividades de $\mathrm{m}$-learning em matemática. 2011. Doutorado em Informática na educação. Programa de Pós-Graduação em Informática na Educação, Universidade Federal do Rio Grande do Sul, Porto Alegre, 2011.

BICUDO, Maria Aparecida Viggiani (org.). Pesquisa em Educação Matemática: Concepções \& Perspectivas. São Paulo: Editora da UNESP, 1999.

BICUDO, Maria Aparecida Viggiani; BORBA, Marcelo de Carvalho (Org.). Educação Matemática: pesquisa em movimento. São Paulo: Cortez, 2004.

BISSI, Tiago. As potencialidades pedagógicas da História da Matemática - Uma abordagem com alunos da 8a série. Revista de História da Matemática Para Professores, Natal, p.39-57, mar. 2014.

BLUM, W. Quality teaching of mathematical modelling: What do we know, what can we do?. In: THE PROCEEDINGS OF THE 12TH INTERNATIONAL CONGRESS ON MATHEMATICAL EDUCATION. Proceedings... Springer, Cham, p. 73-96, 2015.

BRAÚNA, J. R. F. Foregrounds e intenção de aprendizagem na Educação Matemática: narrativas de estudantes em uma escola de tempo integral no município de Mossoró/RN. Dissertação (Mestrado em Ensino) - UERN, UFERSA e IFRN, Mossoró/RN, 2020.

BZUNECK, J. A.; MEGLIATO, J. G. P.; RUFINI, S. E. Engajamento de adolescentes nas tarefas escolares de casa: uma abordagem centrada na pessoa. Psicologia Escolar e Educacional, v. 17, n. 1, p. 151-161, 2013.

CAMARGO, C. A. C. M.; CAMARGO, M. A. F.; SOUZA, V. O. A importância da motivação no processo ensino-aprendizagem. Revista Thema, v. 16, n. 3, p. 598-606, 2019.

COCK, Dagfinn; HALVARI, Hallgeir. Motivation, performance and satisfaction at school. In: EFKLIDES, Anastasia; KUHL, Julius; SORRENTINO, Richard M. Trends and prospects in motivation research. p. 65-84, 2001. doi: 10.1007/0-306-47676-2. 
COSTA, L. B. Cartografia: uma outra forma de pesquisar. Revista Digital do Laboratório de Artes Visuais. Santa Maria (RS), v. 7, n. 2, p. 66 -77 - mai./ago. 2014.

CRUZ, Jaqueline Valério da; SILVA, Paulo Vilhena da. Jogos e objetos matemáticos como recurso pedagógico: terapia wittgensteiniana dos conceitos psicológicos. BOEM - Boletim online de Educação Matemática, v.7, n.14, p.43-59, 2019.

CURI, E. Formação de professores polivalentes: uma análise de conhecimentos para ensinar Matemática e de crenças e atitudes que interferem na constituição desses conhecimentos. PUC/SP, 2004.

CURI, E. A matemática e os professores dos anos iniciais: uma análise dos conhecimentos para ensinar matemática e das crenças e atitudes que interferem na constituição desses conhecimentos. Musa Editora, 2005.

CURY, H.N; LEIVAS, J.C. Atividades com fractais em uma proposta de inovação curricular para cursos de formação de professores. Disponível em: http://limc.ufrj.br/htem4/papers/8.pdf. Acesso em: 22 de outubro de 2018.

D’AMBRÓSIO, Ubiratan. Educação Matemática: da teoria à prática. 2. ed. Campinas: Papirus, 1997. D’AMBROSIO, B. S. A subversão responsável na constituição do educador matemático. In Obando, G. (Ed.). 16 Encuentro Colombiano de Matemática Educativa (pp. i-xx). Bogotá, Colombia: Asociación Colombiana de Matemática Educativa, p. 1-8, 2015

D'AMBROSIO, Beatriz S.. Reflexões sobre a história da matemática na formação de professores. Revista Brasileira de História da Matemática, São Paulo, p.399-406, dez. 2007.

Davis J. Charlene; Swanson, Scott T. Navigating satisfactory and dissatisfactory classroom incidents. Journal of Education for Business, v.76, n.5, p.245-250, 2001. doi: 10.1080/08832320109599643.

DE ALMEIDA, M. B.; DE LIMA, M. G. Formação inicial de professores e o curso de pedagogia: reflexões sobre a formação matemática. Ciência \& Educação (Bauru), v. 18, n. 2, p. 451-468, 2012. DELEUZE, G.; GUATTARI, F. Introdução: Rizoma. In: Mil Platôs: capitalismo e esquizofrenia. (Volume 1) Rio de Janeiro: Editora 34, 1995. p. 10 - 39. (Tradução de Aurélio Guerra Neto).

DUVAL, R. Registros de representação semiótica e funcionamento cognitivo do pensamento. Registres de représentation sémiotique et fonctionnement cognitif de la pensée. Trad. Méricles Thadeu. Revista Eletrônica de Educação Matemática - Revemat [s.I.], v. 7, n. 2, p.266-297, dez. 2012. UFSC.

DUVAL, R. Semiosis y pensamento humano: Registros semióticos y Aprendizajes intelectuales. Trad. Myriam Vega Restrepo. Cali, Colombia: Universidade del Valle, 1999.

FARIA, A. F.; DE MOURA VAZ, A. Engajamento de Estudantes em Investigação Escolar sobre Circuitos Elétricos Simples. Ensaio Pesquisa em Educação em Ciências, v. 21, 2019

FERREIRA, N. S. Modelagem Matemática e Tecnologias de Informação e Comunicação como ambiente para abordagem do conceito de Função segundo a Educação Matemática Crítica. $243 \mathrm{f}$. Dissertação (Mestrado) - Universidade Federal de Ouro Preto, Ouro Preto, 2013.

FIORENTINI, Dario (Org.). Formação de Professores de Matemática: explorando novos caminhos com outros olhares. Campinas: Mercado das Letras, 2003.

FIORENTINI, Dario (org.). Grupo de sábado: uma história de reflexão, investigação e escrita sobre a prática escolar em Matemática. In: FIORENTINI, D.; CRISTÓVÃO, E. M. (org.). Histórias e investigação de/em aulas de Matemática. Campinas, SP: Editora Alínea, 2006.

FIORENTINI, Dario. Alguns modos de ver e conceber o ensino da matemática no Brasil. Zetetiké, Campinas, n. 4, p. 1-37, nov. 1995.

FOUCAULT, M. Microfísica do Poder, Rio de Janeiro: Edições Graal Ltda, 1979. 
GARNICA, A. V. M. (Org.). Oral History and Mathematics Education. 1ed. Cham (Alemanha): Springer, 2019.

GARNICA, A. V. M. Registrar oralidades, analisar narrativas: sobre pressupostos da História Oral em Educação Matemática. Ciências Humanas e Sociais em Revista, v. 32, p. 20-35, 2010.

GARNICA, A.V. M.; SILVA, H.; FERNANDES, D. N. História Oral: pensando uma metodologia para a Educação Matemática. Anais do V Congresso Internacional de Ensino da Matemática (V CIEM). ULBRA, 2010.

GAUTHIER, J. Sociopoética e formação do pesquisador integral. Revista Psicologia, Diversidade e Saúde. P. 78-86. Salvador, 2015.

GUATTARI, F., ROLNIK, S. Micropolíticas: cartografias do desejo. Petrópolis: Vozes, 2005

HALBWACHS, M. A Memória Coletiva. São Paulo: Centauro, 2006.

KAISER, G. Mathematical modelling and applications in education. Encyclopedia of mathematics education, p. 396-404, 2014.

KALINKE, Marco Aurélio; MOCROSKY, Luciane Ferreira (Org.) Educação Matemática: pesquisas e possibilidades. Curitiba: UTFPR Editora, 2015.

LARROSA, J. Tremores: escritos sobre experiência. Belo Horizonte: Autêntica, 2016.

LOPES, Anemari Roesler Luersen Vieira; BORBA, Marcelo de Carvalho. Tendências em Educação Matemática. Revista Roteiro, v. XVI, n. 32, jul/dez, p. 49-61, 1994.

MALHEIROS, A. P. S. Pesquisas em Modelagem Matemática e diferentes tendências em Educação e em Educação Matemática. Bolema, v. 26, n. 43, p. 861-882, 2012.

MARTINS, E R; Geraldes, W. B.; AFONSECA, U. R.; GOUVEIA, L. M. B. Tecnologias Móveis em Contexto Educativo: uma Revisão Sistemática da Literatura. RENOTE: Novas Tecnologias na Educação, Porto Alegre, v. 16, n. 1, julho, 2018.

MASINI, Elcie Aparecida Fortes Salzano; MOREIRA, Marco Antônio. Aprendizagem significativa: a teoria de David Ausubel. São Paulo: Moraes, 1982.

MIGUEL, Antonio. As potencialidades pedagógicas da história da matemática em questão: argumentos reforçadores e questionadores. Zetetiké, Campinas, v. 5, n. 8, p. 90-105, 1997.

MIGUEL, Antonio; GARNICA, Antonio Vicente Marafioti; IGLIORI, Sonia Barbosa Camargo; D’AMBRÓSIO, Ubiratan. A educação matemática: breve histórico, ações implementadas e questões sobre sua disciplinarização. Revista Brasileira de Educação, n. 27, p. 70-93, 2004.

MORAIS, M. B. Se um viajante... Percursos e Histórias sobre a formação de professores de matemática no Rio Grande do Norte. Tese (Doutorado em Educação Matemática) - Instituto de Geociências e Ciências Exatas, UNESP, Rio Claro, 2017.

MOREIRA, Marco Antônio. A teoria da Aprendizagem Significativa segundo Ausubel. IN: MASINI, Elcie Aparecida Fortes Salzano; MOREIRA, Marco Antônio (Org.). Aprendizagem significativa: condições para ocorrência e lacunas que levam a comprometimentos. São Paulo: Vetor, 2008a.

MOREIRA, Marco Antônio. Aprendizaje significativo: un concepto subyacente. In: ENCUENTRO INTERNACIONAL SOBRE EL APRENDIZAJE SIGNIFICATIVO, 2., 1997, Burgos. Actas... Burgos (Espanha), 1997.

MOREIRA, Marco Antônio. O que é afinal aprendizagem significativa. In: MOREIRA, Marco Antônio Aprendizagem significativa: a teoria e textos complementares. São Paulo: Livraria de Física, 2011. MOREIRA, Marco Antônio. Organizadores previos y aprendizaje significativo. Revista Chilena de Educación Científica, v. 7, n. 2, p. 23-30, 2008b. Disponível em: https://www.if.ufrgs.br/ moreira/ORGANIZADORESesp.pdf. Acesso em: 14 jan. 2019. 
MOREIRA, Marco Antônio; MASINI, Elcie Aparecida Fortes Salzano. Aprendizagem significativa: a teoria de David Ausubel. 2. ed. São Paulo: Centauro, 2006.

MORETTI, M.T. O papel dos registros de representação na aprendizagem matemática.

Contrapontos: Revista do Programa de Pós-Graduação em Educação da Univali. ISSN: 1984-7114. Itajaí, v. 02, n. 6, p. 423-437, 2002.

MORIN, E. A noção de sujeito. In: SCHNITMAN, D. F. (orga.). Novos paradigmas, cultura e subjetividade. Porto Alegre: Artes Médicas, 1996.

NACARATO, A. M. Educação continuada sob a perspectiva da pesquisa-ação: currículo em ação de um grupo de professoras ao tentar aprender ensinando Geometria. 2000. Tese de Doutorado. Tese (Doutorado). Campinas, SP: FE/Unicamp.

NACARATO, Adair Mendes. Educação continuada sob a perspectiva da pesquisa-ação: currículo em ação de um grupo de professoras ao aprender ensinando Geometria. 2000. Tese (Doutorado em Educação) - Faculdade de Educação, Unicamp, Campinas, 2000.

NÓVOA, António Sampaio da (coord.). Os professores e a sua formação. 2. ed. Lisboa: Dom Quixote, 1995a.

NÓVOA, António Sampaio da (org.). Profissão professor. Porto: Porto Editora, 1995b.

NÓVOA, António Sampaio da (org.). Vidas de professores. Porto: Porto Editora, 1992b.

NÓVOA, António Sampaio da. A formação contínua de professores: realidades e perspectivas. Aveiro: Universidade de Aveiro, 1991.

NÓVOA, António Sampaio da. Formação de professores e profissão docente. In: NóVOA, A. (org.). Os professores e sua formação. Lisboa: Instituto de Inovação Educacional, 1992a. p. 139-158. NÓVOA, António Sampaio da. Formação de professores e trabalho pedagógico. Lisboa, Portugal: Educa, 2002.

PASSOS, E.; KASTRUP, V.; ESCÓSSIA, L. Pistas do método da cartografia: pesquisa-intervenção e produção de subjetividade. Porto Alegre: Sulina, 2009.

PAVANELLO, R. M. A Geometria nas séries iniciais do ensino fundamental: contribuições da pesquisa para o trabalho escolar. Matemática nas séries iniciais do ensino fundamental: a pesquisa e a sala de aula. São Paulo: SBEM, p. 129-143, 2004b.

PAVANELLO, R. M. et al. Formação de possibilidades cognitivas em noções geométricas. 1995.

PAVANELLO, R. M. et al. Formação de possibilidades cognitivas em noções geométricas. 1995.

PAVANELLO, R. M. O abandono do ensino da Geometria no Brasil: causas e consequências. Zetetiké, v. 1, n. 1, 1993.

PAVANELLO, R. M. Por que ensinar/aprender Geometria. VII Encontro Paulista de Educação Matemática, 2004a.

PAVANELLO, R. M. O abandono do ensino de Geometria: uma visão histórica. 1989. 196 f. 1989. Tese de Doutorado. Dissertação (Mestrado em Educação) -Faculdade de Educação, Universidade Estadual de Campinas, São Paulo.

PIAGET, J. Estudos sociológicos. 1a Edição. Rio de Janeiro: Forense, 1973.

PLOMP, T.; NIEVEEN, N. Educational design research part A: An introduction. Enchede, The Netherlands: SLO, 2013.

RAMOS, R.C.S.S.; TRISCH, E.; SALVI, R. F. Modelagem Matemática como possibilidade de motivação do aluno - o caso da feira de matemática. in: II CNEM - CONGRESSO NACIONAL DE EDUCAÇÃO MATEMÁTICA, IX EREM - ENCONTRO NACIONAL DE EDUCAÇÃO MATEMÁTICA, v. 2, n. 23, 2011, Ijuí, RS. Anais... UNIJUII, ljuí, p. 1-13, 2011. 
REIS, Pedro Rocha dos. As narrativas na formação de professores e na investigação em educação. Nuances: Estudos sobre Educação, Presidente Prudente, SP, ano XIV, v. 15, n. 16, p. 17-34, jan./dez. 2008.

RIBEIRO, O. C. Criatividade na pesquisa acadêmica: método-caminho na perspectiva de uma fenomenologia complexa e transdisciplinar. Revista Terceiro Incluído, v. 5, n. 1, p. 189-215. 2015.

RODRIGUES, M. A. S.; Healy, L. MusiCALcolorida: formas musicais e coloridas para representar e explorar números. 2008.

SANTOS, Luciane Mulazani dos Santos; DAMÁZIO JÚNIO, Valdir. Pós-modernidade, cultura e tendências em Educação Matemática. In: KALINKE, Marco Aurélio; MOCROSKY, Luciane Ferreira (Org.) Educação Matemática: pesquisas e possibilidades. Curitiba: UTFPR Editora, 2015.

SHULMAN, Lee. Those who understand: Knowledge growth in teaching. Educational Researcher 15(2), 1986, p. 4-14.

SILVA, C. Aprendizagem Significativa em atividades de Modelagem Matemática, $145 \mathrm{f}$. Tese (Doutorado em Ensino de Ciências e Educação Matemática) Instituição de Ensino) - Universidade Estadual de Londrina, Londrina, 2018.

SILVEIRA, L.; ALMEIDA, A.; MACEDO, S.; ALENCAR, M.; ARAUJO, M.. A Sociopoética como dispositivo para a produção de conhecimento. Interface: comunicação e saúde. v. 12 a 27, p. 873881, out/dez 2008.

SKOVSMOSE, O. Um convite à Educação Matemática Crítica. Trad. Orlando de Andrade Figueiredo - Campinas, SP: Papirus, 2014.

SONEGO, A. H. S. Arqped-mobile: Uma arquitetura pedagógica com foco na aprendizagem móvel. 2019. Doutorado em Educação. Programa de Pós-Graduação da Faculdade de Educação, Universidade Federal do Rio Grande do Sul, Porto Alegre, 2019.

SOUZA, D. S. P. Formação subjetiva dos alunos e a educação escolar: a influência dos espaços no processo de ensino na escola pública. Dissertação (Mestrado em Ensino) - UERN, UFERSA e IFRN, Mossoró/RN, 2020.

SULTAN, Parves; WONG, Ho Yin. Antecedents and consequences of service quality in a higher education context: a qualitative research approach. Quality Assurance in Education, v.21, n.1, p.70-95, 2013. doi: 10.1108/09684881311293070.

TARDIF, Maurice. Saberes docentes e formação profissional. 12. ed. Petrópolis, RJ: Vozes, 2003. VALENTE, José Armando. A Espiral da Espiral de Aprendizagem: o processo de compreensão do papel das tecnologias de informação e comunicação na educação. 2005. Tese (Livre Docência) Universidade Estadual de Campinas. Campinas, 2005.

VALSINER, Jaan. Mundos da mente, mundos da vida: fundamentos da psicologia cultural. Porto Alegre: Artmed, 2012.

VIDIGAL, C. L. Desenvolvendo criticidade e criatividade com estudantes de geografia por meio de modelagem. 148 f. Dissertação (Mestrado Profissional em Educação Matemática) - Universidade Federal de Ouro Preto, Ouro Preto, 2013.

WHITE, T.; MARTIN, L. Mathematics and Mobile Learning. TECHTRENDS. v. 58, p.64-70, 2014. WOODWARD, K. Identidade e diferença: uma introdução teórica e conceitual. In: Identidade $e$ diferença: a perspectiva dos Estudos Culturais. Petrópolis: Vozes, 2012. 